\title{
Media Informasi Berbentuk Video Promosi Pada SMK Islam Terpadu Indra Bangsa Tangerang
}

\author{
Giandari Maulani* $^{1}$, Nuryahya Ibrahim ${ }^{2}$, Farahdina Agustine ${ }^{3}$ \\ ${ }^{1,2}$ Program Studi Sistem Informatika, Fakultas Sains and Teknologi, Universitas Raharja \\ ${ }^{3}$ Program Studi Teknik Informatika, Fakultas Sains and Teknologi, Universitas Raharja \\ Email: ${ }^{* 1}$ giandari@ raharja.info ${ }^{2}$ nuryahya@ raharja.info, \\ farahdina.agustine@ raharja.info
}

\begin{abstract}
Abstrak
Video promosi merupakan sebuah media elektronik untuk menyampaikan informasi yang sangat efektif dalam memperkenalkan sebuah sekolah, melalui media visual inilah maka semua informasi dapat dengan mudah dipahami oleh semua kalangan masyarakat. Permasalahan yang terdapat pada SMK Islam Terpadu Indra Bangsa Tangerang dalam strategi promosinya masih menggunakan media cetak seperti spanduk dan brosur, media sosial seperti facebook yang belum update sehingga kurang maksimal dalam memberikan informasinya. Tujuan dari penelitian ini yaitu untuk memberikan informasi berupa video promosi yang informatif dan menarik tentang profil sekolah, fasilitas, keunggulan, prestasi dan berbagai kegiatan di SMK Islam Terpadu Indra Bangsa Tangerang. Strategi pemasaran media video promosi ini akan diimplementasikan melalui channel youtube dan social media yaitu facebook, serta video promosi ini akan diputar di LCD sekolah khususnya di bagian pendaftaran sekolah dan akan dipresentasikan juga pada berbagai acara sekolah seperti pertemuan wali murid dan berbagai kegiatan kunjungan ke sekolah-sekolah SMP relasi. Metode penelitian yang digunakan yaitu pengumpulan data yang terdiri dari observasi, wawancara dan studi pustaka, analisis SWOT, analisis perancangan media, dan konsep produksi media (KPM) yang terdiri dari preproduction, production, dan postproduction. Video promosi ini dirancang dengan software Adobe Premiere Pro CS6, Adobe After Effects CS6 dan Adobe Photoshop CS6. Melalui media video promosi ini, akan membantu sekolah dalam menginformasikan dan mempromosikan sekolah, sehingga banyak masyarakat yang mengetahui sekolah tersebut, dan tertarik untuk bersekolah di SMK Islam Terpadu Indra Bangsa. Dari rancangan media video promosi yang dihasilkan diharapkan dapat bermanfaat bagi semua pihak.
\end{abstract}

Kata Kunci - Video Promosi, Media, Informasi.

\begin{abstract}
Promotional video is an electronic media to convey information that is very effective in introducing a school, through this visual media all information can be easily understood by all people. The problems found in the Indra Bangsa Integrated Islamic Vocational School in Tangerang are still using printed media such as banners and brochures, social media such as Facebook which has not been updated so that it is not optimal in providing information. The purpose of this study is to provide information in the form of informative and interesting promotional videos about school profiles, facilities, excellence, achievements and various activities at the Indra Bangsa Islamic Integrated Vocational School, Tangerang. This promotional video media marketing strategy will be implemented through YouTube and social media channels, namely Facebook, and this promotional video will be played on school LCDs, especially in the school registration section and will also be presented at various school events such as student guardian meetings and various school visit activities. relation junior high school. The research method used is data collection consisting of observation, interviews and
\end{abstract}


literature study, SWOT analysis, media design analysis, and the concept of media production (KPM) which consists of preproduction, production, and postproduction. This promotional video is designed with Adobe Premiere Pro CS6, Adobe After Effects CS6 and Adobe Photoshop CS6 software. Through this promotional video media, it will assist schools in informing and promoting the school, so that many people know about the school, and are interested in attending Indra Bangsa Integrated Islamic Vocational School. From the design of the promotional video media produced, it is hoped that it can be useful for all parties.

Keywords - Promotional Videos, Media, Information

\section{PENDAHULUAN}

Perkembangan zaman yang terus berkembang membuat perubahan dalam promosi pemasaran juga berubah. Di zaman era globalisasi saat ini semakin terasa terutama dalam perkembangan teknologi komputer khususnya dalam bidang multimedia audio visual dan broadcasting. Terobosan baru dalam bidang multimedia semakin banyak bermunculan dikarenakan semakin luasnya kebutuhan informasi pada masyarakat yang membuat terciptanya inovasi dalam bidang multimedia. Banyak Perusahaan serta lembaga menggunakan teknologi sebagai media informasi serta promosi. ${ }^{[1]}$.

Yayasan merupakan badan hukum yang telah lama ada dan digunakan oleh masyarakat Indonesia dalam berbagai maksud dan tujuan umumnya sosial, didalam undang-undang No 16 Tahun 2001 tentang yayasan pasal 1 angka 1 yang jelas menyebutkan bahwa tujuan yayasan adalah di bidang sosial, keagamaan dan kemanusiaan ${ }^{[2]}$.

SMK Islam Terpadu Indra Bangsa beralamat di Jl. Kh. Mustofa No.27, RT.05/03, Kel. Poris Gaga Baru, Kec. Tangerang, Kota Tangerang, Banten 15122. Sekolah ini memiliki Program Studi Teknik Komputer Jaringan (TKJ), selain itu juga memiliki berbagai fasilitas seperti laboratorium komputer, masjid, area parkiran, lapangan olahraga dan BLK (Balai Latihan Kerja).

Permasalahan yang terdapat pada SMK Islam Terpadu Indra Bangsa yaitu dalam memberikan informasi kepada masyarakat sebelumnya kurang efektif, karena masih menggunakan media cetak seperti spanduk dan brosur, media sosial seperti facebook sebagai media promosinya,selain itu SMK Islam Terpadu Indra Bangsa pada tahun 2018 calon pendaftar sebanyak 102 siswa/siswi baru dan pada tahun 2019, hanya terdapat sedikit peningkatan jumlah calon siswa/siswi baru yaitu sebanyak 6 siswa menjadi 108 siswa/siswi.

Tujuan penelitian ini yaitu untuk menginformasikan dan mempromosikan sekolah serta meningkatkan jumlah pendaftaran siswa/siswi baru yang bergabung di SMK Islam Terpadu Indra Bangsa.

Hasil dari penelitian ini yaitu untuk menghasilkan media video promosi yang akan memberikan informasi lengkap, menarik dan update mengenai : profil sekolah, program studi, fasilitas, keunggulan, prestasi, ekstrakurikuler dan berbagai kegiatan (hadroh, marawis, pidato dan tahfidz) di SMK Islam Terpadu Indra Bangsa. Untuk itu Video promosi pada SMK Islam Terpadu Indra ini akan diimplementasikan melalui DVD, youtube dan facebook. Serta video promosi ini akan diputar di $L C D$ sekolah khususnya di bagian pendaftaran sekolah dan akan dipresentasikan juga pada berbagai acara sekolah seperti pertemuan wali murid dan berbagai kegiatan kunjungan ke sekolah-sekolah SMP relasi.

Melalui pengembangan media video promosi ini, akan menginformasikan dan mempromosikan sekolah serta meningkatkan jumlah pendaftaran siswa/siswi baru yang bergabung di SMK Islam Terpadu Indra Bangsa.

\section{METODE PENELITIAN}

Metode yang digunakan dalam penelitian ini yaitu : (1) Metode Pengumpulan Data, metode ini digunakan dengan cara melakukan Observasi, wawancara dan Studi pustaka. (2) 
Analisis SWOT, metode ini merupakan manajemen strategis yang digunakan untuk mengevaluasi kekuatan, kelemahan, peluang, dan ancaman. (3) Analisa Perancangan Media, metode ini menggunakan Software yang dipakai untuk mengedit video yaitu Adobe Premiere Pro CS6, Adobe After Effects CS6 dan Adobe Photoshop CS6. (4) Konsep Produksi Media (KPM) terdiri dari :Pre Production, Production dan Post Production.

\section{Literature Review}

Berikut adalah beberapa penelitian yang berkaitan dengan media video Promosiini yaitu sebagai berikut :

1. Penelitian yang dilakukan oleh Maulani, dkk (2016) dengan judul"Pengembangan Media Promosi Pariwisata Kota Tangerang Dalam Bentuk Video Digital Pada Dinas Porparekraf" Penelitian yang membahas tentang merancang media audio visual pariwisata Kota Tangerang software Addobe Premiere CC, Adobe After Effect CC, dan Adobe Illustrator $C C{ }^{[3]}$

2. Penelitian yang dilakukan Sunarya, dkk(2018)yang berjudul "Video Promosi Jurusan Sistem Informasi Berbasis Motion Graphic Pada STMIK Raharja Tangerang" penelitian ini Perancangan video promosi berbasis motion graphic 2D yang menggunakan video dan animasi untuk menciptakan ilusi dari gerak ataupun transformasi, dalam pembuatannya ada Metode menggunakan aplikasi program komputer grafis diantaranya : After Effects Cs6, Adobe Illustrator Cs6, dan Adobe Audition Cs6 dan Metode Konsep Produksi Media (KPM). ${ }^{[4]}$

3. Penelitian yang dilakukan oleh Hardiansyah, dkk (2018) dengan berjudul "Video Profile Sebagai Media Penunjang Informasi Dan Promosi Pada SMK Putra Tama Mandiri" penelitian ini bertujuan untuk media informasi kepada masyarakat luas khususnya dalam dunia pendidikan.Dalam pembuatannya ada Metode Adobe Photosop, Adobe Premiere Pro. ${ }^{[5]}$

4. Penelitian yang dilakukan Permana, dkk (2017) dengan berjudul "Video Profil Sebagai Sarana Promosi Efektif Dalam Menunjang Eksistensi Program Studi Manajemen Informatika", Tujuan adanya penelitian ini yaitu untuk meningkatkan jumlah mahasiswa, penelitian ini menggunakan Metode Pengumpulan Data. Dan menggunakan software :Adobe Premiere Pro. ${ }^{[6]}$

5. Penelitian yang dilakukan oleh Wiratna, dkk (2017)dengan berjudul "Perancangan Video Promosi Wisata Pantai Kabupaten Jember dengan Konsep Sinematik Infografis", Tujuan dari adanya penelitian ini yaitu untuk mempromosikan lokasi wisata di sebuah daerah dengan tujuan tertentu dibidang pariwisata. Metode yang digunakan dalam penelitian ini yaitu metode pra riset, riset dan Kesimpulan Hasil Penggalian Data. dengan menggunakan software pendukung seperti: Adobe Premiere Pro. ${ }^{[7]}$

\section{HASIL DAN PEMBAHASAN}

\subsection{Preproduction}

Pre production merupakan tahapan awal dalam menentukan sebuah ide cerita kemudian membuat sketsa beberapa adegan penting ke dalam bentuk naskah cerita lalu dilanjutkan dengan tahapan membuat sinopsis, narasi, storyboard, script writing, rundown, penyusunan crew, time schedule. anggaran atau budget, dengan tahapan terakhir yaitu mempersiapkan peralatan yang akan digunakan selama melakukan proses produksi.Berikut ini merupakan alur dari Pre productionpada gambar 1 dibawah ini. 
1. Ide/Gagasan

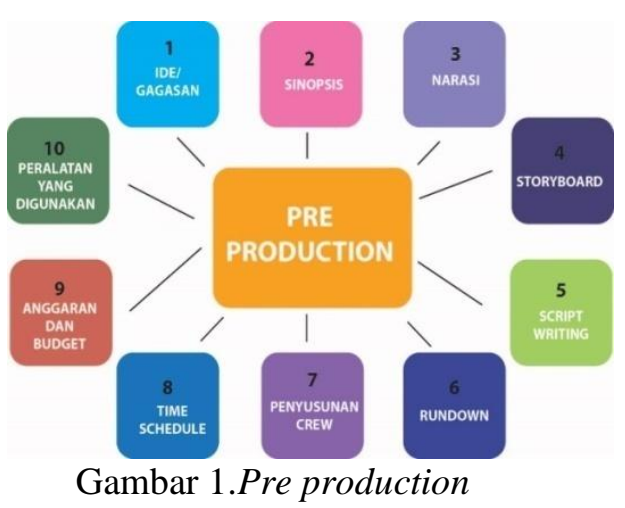

Pada tahapan pre production, yaitu dengan menemukan sebuah ide atau gagasan yang direalisasikan dalam bentuk video. Ide atau gagasan merupakan sebuah proses paling awal yang harus dilakukan ketika dalam perencanaan pembuatan sebuah video. Dalam pembuatan video promosi SMK Islam Terpadu Indra Bangsa ini, diperlukan gagasan yang menarik dalam penyampaian informasi mengenai keseluruhan ruang lingkup yang terdapat pada SMK Islam Terpadu Indra Bangsa yaitu profil sekolah, fasilitas, keunggulan, prestasi, ekstrakurikuler dan berbagai kegiatan sekolah.

2. Sinopsis atau Cerita

Sinopsis merupakan sebuah ringkasan inti cerita dari alur cerita yang panjang yang dapat dijelaskan dengan jelas dari alur cerita tersebut. Langkah awal pembuatan sinopsis yaitu dengan menentukan kerangka cerita yang terdapat di dalamnya judul, tokoh, latar, konflik, dan alur cerita. Berikut ini sinopsis dari video Promosi SMK Islam Terpadu Indra Bangsa:

"Diawal video menampilkan Bumper Opening. Selanjutnya menampilkan tulisan nama SMK Islam Terpadu Indra Bangsa Tangerang. Lalu papan nama SMK Islam Terpadu Indra Bangsa Tangerang. Kemudian kedatangan siswa/i SMK Islam Terpadu Indra Bangsa Tangerang. Lalu menampilkan gedung SMK Islam Terpadu Indra Bangsa Tangerang. Kemudian profil SMK Islam Terpadu Indra Bangsa Tangerang, visi \& misi SMK Islam Terpadu Indra Bangsa Tangerang dan akreditasi sekolah. Kemudian menampilkan program studi SMK Islam Terpadu Indra Bangsa Tangerang. Lalu menampilkan video kegiatan belajar mengajar di Kelas, menampilkan ruang kelas, ruang kepala sekolah, ruang guru, ruang administrasi, ruang laboratorium komputer. Lalu menampilkan fasilitas masjid, lapangan parkir, lapangan olahraga. Kemudian menampilkan keunggulan BLK (Balai Latihan Kerja). Lalu menampilkan suasana sholat dhuha siswa/i. Kemudian menampilkan prestasi. Lalu menampilkan kegiatan hadroh, kegiatan marawis, kegiatan pidato, kegiatan tahfidz. Lalu menampilkan ekstrakurikuler pramuka, ekstrakurikuler paskibra dan ekstrakurikuler DKV. Kemudian menampilkan ajakan bergabung di SMK Islam Terpadu Indra Bangsa Tangerang. Selanjutnya menampilkan Alamat, Nomor Telepon, Email, Logo dan Nama SMK Islam Terpadu Indra Bangsa Tangerang ”.

\section{Narasi}

Narasi adalah sebuah rangkaian peristiwa/cerita yang terjadi. Sebuah paragraf di dalam suatu rangkaian peristiwa yang terjadi dari waktu ke waktu yang dijabarkan dari awal, tengah dan akhir.Berikut ini adalah narasi dubbing pada Media Video Sebagai Penunjang Promosi Pada SMK Islam Terpadu Indra Bangsa:

SMK Islam Terpadu Indra Bangsa berada di Jalan Kh. Mustofa No // 27/ RT // 05 /03 / Kel // Poris Gaga Baru / Kec // Tangerang / Kota Tangerang/ Banten // SMK Islam Terpadu 
Indra Bangsa memiliki fasilitas gedung 2 lantai // SMK Islam Terpadu Indra Bangsa Tangerang memiliki ruang kelas yang nyaman sehingga terciptanya suasana belajar mengajar yang efektif/l Biaya sekolah yang terjangkau dan lulusan SMK Islam Terpadu Indra Bangsa dapat bersaing dengan lulusan sekolah agama lainnya // Keunggulan yang dimiliki SMK Islam Terpadu Indra Bangsa Tangerang adalah mempunyai BLK (Balai Latihan Kerja) siswa/i bisa merakit komputer (bongkar dan pasang komputer) dan keunggulan yang lebih diutamakan sekolah SMK Islam Terpadu Indra Bangsa adalah sekolah yang berorientasi pada nilai-nilai Islami // Visi dan misi SMK Islam Terpadu Indra Bangsa // SMK Islam Terpadu Indra Bangsa memiliki Akreditasi B // SMK Islam Terpadu Indra Bangsa Tangerang mempunyai program studi Teknik Komputer Jaringan (TKJ) // Berikut ini adalah ruang kelas SMK Islam Terpadu Indra Bangsa / ruang kepala sekolah SMK Islam Terpadu Indra Bangsa / ruang guru SMK Islam Terpadu Indra Bangsa / ruang administrasi SMK Islam Terpadu Indra Bangsa / dan ruang Laboratorium Komputer SMK Islam Terpadu Indra Bangsa dilengkapi dengan akses internet // Berikut ini fasilitas SMK Islam Terpadu Indra Bangsa // fasilitas masjid / fasilitas area parkiran / fasilitas lapangan olahraga / dan fasilitas BLK (Balai Latihan Kerja) // Berikut ini suasana sholat dhuha berjamaah siswa/i // prestasi SMK Islam Terpadu Indra Bangsa // Berikut ini kegiatan tambahan SMK Islam Terpadu Indra Bangsa // kegiatan hadroh / kegiatan marawis / kegiatan pidato / dan kegiatan tahfidz // Berikut ini ekstrakulikuler SMK Islam Terpadu Indra Bangsa // ekstrakurikuler pramuka / ekstrakurikuler paskibra / dan ekstrakurikuler DKV // SMK Islam Terpadu Indra Bangsa memiliki prestasi baik dibidang akademik maupun non-akademik // Bagi teman-teman yang ingin memiliki Aqidah yang kuat, beribadah dengan benar dan berakhlak mulia bergabunglah bersama kami di SMK Islam Terpadu Indra Bangsall

\section{Storyboard}

Storyboard adalah sebuah gambar sket/catatan pengambilan gambar untuk membuat film. Berikut adalah Storyboard yang sudah digambarkan per-scene, berdasarkan alur cerita yang dirancang pada video promosi SMK Islam Terpadu Indra Bangsa. Pada gambar 2, scene 1, Menampilkan video Bumper Opening Logo SMK Islam Terpadu Indra Bangsa. Gambar 3, scene 2, Menampilkan Tulisan Nama Sekolah dengan angle kamera medium shot. Lalu gambar 4, scene 3, Menampilkan Visi \& Misi SMK Islam Terpadu Indra Bangsa. Lalu di gambar 5, scene 4, Menampilkan Akreditasi Sekolah SMK Islam Terpadu Indra Bangsa. pada gambar 6, scene 5, Menampilkan Video Ruang Kelas SMK Islam Terpadu Indra Bangsa dengan angle kamera medium shot. Pada gambar 7. Scene 6, Menampilkan Video Kegiatan Belajar Mengajar Di Kelas dengan angle kamera medium shot. kemudian gambar 8, Scene 7, Menampilkan Video Ekstrakurikuler paskibra dengan angle kamera long shot. Lalu gambar 9, scene 8, Menampilkan Video Ekstrakurikuler paskibra dengan angle kamera long shot. pada gambar 10, scene 9, Menampilkan Video Ajakan Bergabung di SMK Islam Terpadu Indra Bangsa dengan angle kamera medium shot. pada gambar 11, scene 10, Menampilkan Video Logo, Alamat, Nomor Telepon, Youtube, Facebook dan Email SMK Islam Terpadu Indra Bangsa.

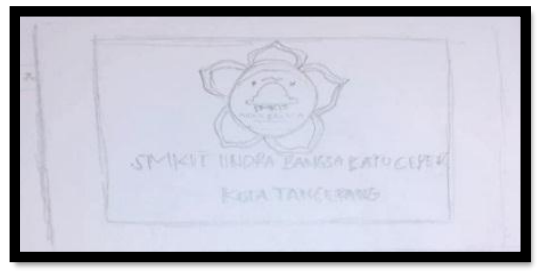

Gambar 2. Scene 1/ Menampilkan videobumper Opening Logo SMK Islam Terpadu Indra Bangsa Tangerang

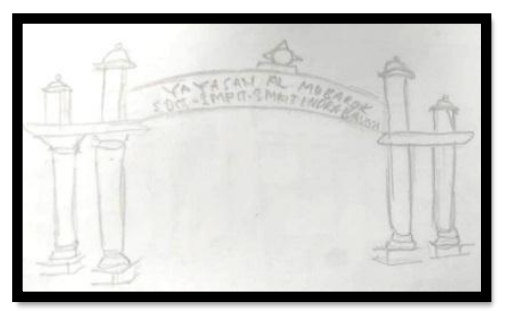

Gambar 3.EXT/Scene 2/ / Day/Medium shot/ Menampilkan Tulisan Nama Sekolah 


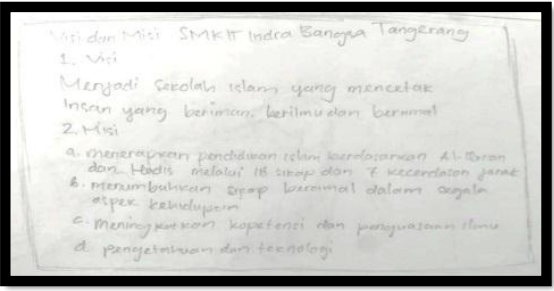

Gambar 4. EXT/ Scene 3/ Menampilkan Visi \& Misi SMK Islam Terpadu Indra Bangsa

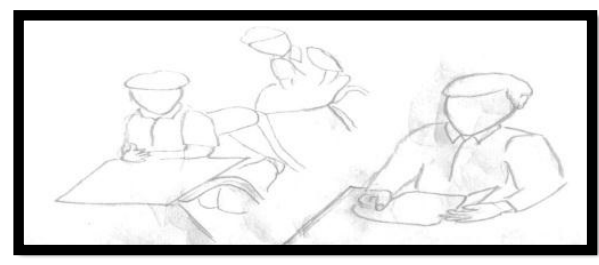

Gambar 6.Scene 5/ Day/ Medium Shoot / Menampilkan Video Ruang Kelas SMK Islam Terpadu Indra Bangsa.

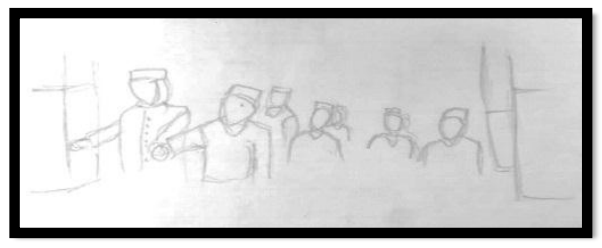

Gambar 8. INT/Scene 7/Day/Long Shot/ Menampilkan Video Ekstrakurikuler Paskibra.

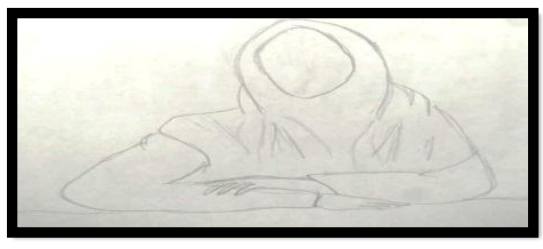

Gambar 10. INT/scene 9/ Day/Medium Shot/ Menampilkan Video Ajakan Bergabung di SMK Islam Terpadu Indra Bangsa

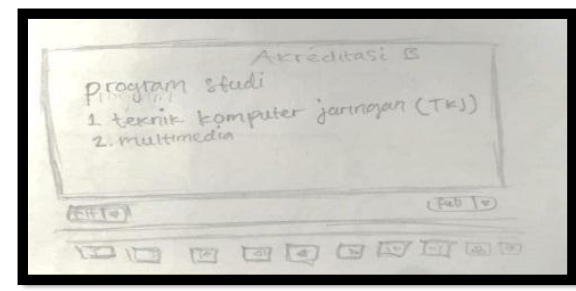

Gambar 5. EXT / Scene 4

Menampilkan Akreditasi Sekolah SMK Islam Terpadu Indra Bangsa

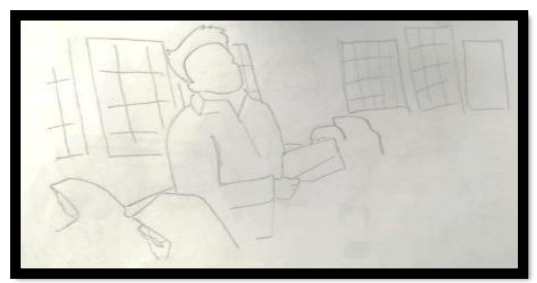

Gambar 7. INT/Scene 6/ Day/Medium Shot/ Menampilkan Video Kegiatan Belajar Mengajar Di Kelas.

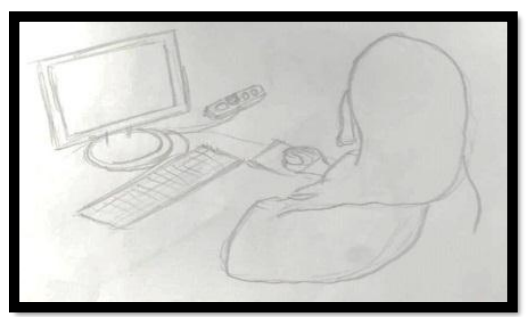

Gambar 9. INT/scene 8/ Day/Over Shoulder shot/ Menampilkan Video Ekstrakurikuler DKV.

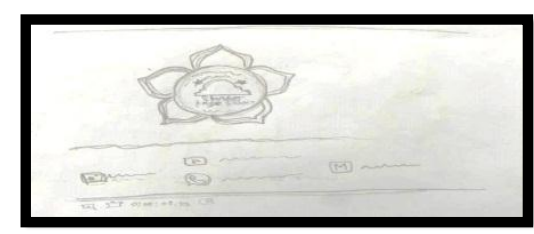

Gambar 11. EXT/scene 10/ Day/ Menampilkan Video Logo, Alamat, Nomor Telepon, Youtube, Facebook dan Email SMK Islam Terpadu Indra Bangsa

\section{Script Writing}

Script Writing dalam pembuatan video promosi pada SMK Islam Terpadu Indra Bangsa ini yakni gambaran alur cerita yang menarik dan detail agar mempermudah proses editing. Berikut ini tabel 1 script writing dari pembuatan video promosi SMK Islam Terpadu Indra Bangsa yaitu: 
Tabel 1. Script Writing

\begin{tabular}{|c|c|c|}
\hline No. & VISUAL & AUDIO \\
\hline 1 & $\begin{array}{l}\text { Menampilkan Bumper Opening Logo } \\
\text { SMK Islam Terpadu Indra Bangsa } \\
\text { Tangerang }\end{array}$ & $\begin{array}{l}\text { Sound Effect (Intro logo } \\
\text { sound pack.mp3) }\end{array}$ \\
\hline 2 & $\begin{array}{l}\text { Menampilkan Tulisan Nama SMK } \\
\text { Islam Terpadu Indra Bangsa } \\
\text { Tangerang }\end{array}$ & $\begin{array}{l}\text { SMK Islam Terpadu Indra Bangsa } \\
\text { berada di Jalan Kh. Mustofa No } \\
\text { // 27/ RT // 05 /03 / (Instrument } \\
\text { Nimbus.mp3) }\end{array}$ \\
\hline 3 & $\begin{array}{l}\text { Menampilkan Visi \& Misi SMK } \\
\text { Islam Terpadu Indra Bangsa } \\
\text { Tangerang }\end{array}$ & $\begin{array}{l}\text { Visi dan misi SMK Islam } \\
\text { Terpadu Indra Bangsa // } \\
\text { (Instrument Nimbus.mp3) }\end{array}$ \\
\hline 4 & Menampilkan Akreditasi Sekolah & $\begin{array}{l}\text { Akreditasi SMK Islam Terpadu } \\
\text { Indra Bangsa B // }\end{array}$ \\
\hline 5 & Menampilkan Ruang Kelas & $\begin{array}{l}\text { ruang kelas SMK Islam Terpadu } \\
\text { Indra Bangsa/(Instrument } \\
\text { Nimbus.mp3) }\end{array}$ \\
\hline 6 & $\begin{array}{l}\text { Menampilkan video kegiatan belajar } \\
\text { mengajar di Kelas }\end{array}$ & $\begin{array}{l}\text { Berikut ini adalah (Instrument } \\
\text { Nimbus.mp3) }\end{array}$ \\
\hline 7 & $\begin{array}{l}\text { Menampilkan Ekstrakurikuler } \\
\text { Paskibra }\end{array}$ & $\begin{array}{l}\text { ekstrakulikuler paskibra / } \\
\text { (Instrument Nimbus.mp3) }\end{array}$ \\
\hline 8 & Menampilkan Ekstrakurikuler DKV & $\begin{array}{l}\text { dan ekstrakulikuler DKV // } \\
\text { (Instrument Nimbus.mp3) }\end{array}$ \\
\hline 9 & $\begin{array}{l}\text { Menampilkan ajakan bergabung di } \\
\text { SMK Islam Terpadu Indra Bangsa } \\
\text { Tangerang }\end{array}$ & $\begin{array}{l}\text { SMK Islam Terpadu Indra Bangsa } \\
\text { memiliki prestasi baik dibidang } \\
\text { akademik maupun non-akademik // } \\
\text { Bagi teman-teman yang ingin } \\
\text { memiliki Aqidah yang kuat, } \\
\text { beribadah dengan benar dan } \\
\text { berakhlak mulia bergabunglah } \\
\text { bersama kami di SMK Islam } \\
\text { Terpadu Indra } \\
\text { Bangsa //(Instrument } \\
\text { Nimbus.mp3) }\end{array}$ \\
\hline 10 & $\begin{array}{l}\text { Menampilkan Logo, Alamat, } \\
\text { Nomor Telepon, Youtube, } \\
\text { Facebook dan Email SMK Islam } \\
\text { Terpadu Indra Bangsa Tangerang }\end{array}$ & (Instrument Nimbus.mp3) \\
\hline
\end{tabular}

6. Rundown

Rundown yaitu susunan cerita yang dirancang oleh durasi waktusaat melakukan shooting atau sebuah acara. Berikut ini pada tabel 2 rundown dari video Promosi SMK Islam Terpadu Indra Bangsa Tangerang: 
Tabel 2.Rundown

\begin{tabular}{|c|c|l|c|c|l|}
\hline No. & Scene & \multicolumn{1}{|c|}{ Location } & Duration & INT/EXT & \multicolumn{1}{|c|}{ Description } \\
\hline 1 & 2 & Tulisan Nama & $00: 10-00: 11$ & EXT & $\begin{array}{l}\text { Mengambil Shot } \\
\text { Tulisan Nama Sekolah }\end{array}$ \\
\hline 2 & 3 & $\begin{array}{l}\text { Kegiatan } \\
\text { Belajar } \\
\text { Mengajar }\end{array}$ & $00: 42-00: 44$ & $I N T$ & $\begin{array}{l}\text { Mengambil Shot } \\
\text { Kegiatan Belajar } \\
\text { Mengajar }\end{array}$ \\
\hline 3 & 4 & Paskibra & $02: 37-02: 41$ & $E X T$ & $\begin{array}{l}\text { Mengambil Shot } \\
\text { Ekstrakurikuler } \\
\text { Paskibra }\end{array}$ \\
\hline 4 & 5 & DKV & $02: 42-02: 43$ & $E X T$ & $\begin{array}{l}\text { Mengambil } \\
\text { Ekstrakurikuler DKV }\end{array}$ \\
\hline 5 & 6 & $\begin{array}{l}\text { Ajakan } \\
\text { Bergabung }\end{array}$ & $02: 44-02: 55$ & $E X T$ & $\begin{array}{l}\text { Mengambil Shot } \\
\text { Ajakan Bergabung }\end{array}$ \\
\hline 6 & 7 & Ruang Kelas & $00: 45-00: 47$ & $I N T$ & $\begin{array}{l}\text { Mengambil Shot } \\
\text { Ruang Kelas }\end{array}$ \\
\hline 7 & 8 & $\begin{array}{l}\text { Laboratorium } \\
\text { Komputer }\end{array}$ & $01: 07-01: 15$ & $I N T$ & $\begin{array}{l}\text { Mengambil Shot } \\
\text { Ruang Laboratorium } \\
\text { Komputer }\end{array}$ \\
\hline 8 & 9 & Prestasi & $01: 58-02: 03$ & INT & $\begin{array}{l}\text { Mengambil Shot } \\
\text { Prestasi }\end{array}$ \\
\hline
\end{tabular}

\section{Penyusunan Crew}

Dalam perancangan media berbasis video promosi sekolah ini, dimana crew merupakan salah satu elemen penting dalam pengambilan gambar, dan berikut susunan crew dalam pembuatan video promosi SMK Islam Terpadu Indra Bangsa Tangerang.

Tabel 3. Susunan Crew

\begin{tabular}{|c|c|c|}
\hline NO. & JABATAN & NAMA \\
\hline 1 & Sutradara & Nuryahya Ibrahim \\
\hline 2 & Cameramen & Nuryahya Ibrahim \\
\hline 3 & Asisten cameramen & Fajar \\
\hline 4 & Editor & Nuryahya Ibrahim \\
\hline 5 & $\begin{array}{c}\text { Sinopsis, Storyboad, } \\
\text { Script Writing dan } \\
\text { Rundown }\end{array}$ & Nuryahya Ibrahim \\
\hline 6 & Dubbing & Zahrotul Hayati \\
\hline 7 & Dokumentasi & Nuryahya Ibrahim \\
\hline 8 & Pemain & $\begin{array}{c}\text { Kepala Sekolah dan Guru } \\
\text { SMK Islam Terpadu Indra } \\
\text { Bangsa Tangerang }\end{array}$ \\
\hline
\end{tabular}


8. Analisa Perancangan Media

Dengan adanya media video sebagai penunjang promosi pada SMK Islam Terpadu Indra Bangsa Tangerang ini menggunakan software pendukung yaitu : Adobe Premiere Pro CS6, Adobe After Effects CS6 dan Adobe Photoshop CS6.

\section{Time schedule}

Time Schedule adalah rencana alokasi waktu untuk menyelesaikan masing-masing item pekerjaan proyek yang secara keseluruhan adalah rentang waktu yang ditetapkan untuk melaksanakan sebuah proyek. Berikut ini pada tabel 4 di bawah ini time schedule Media Video Sebagai Penunjang Promosi Pada SMK Islam Terpadu Indra Bangsa Tangerang:

Tabel 4.Time Schedule

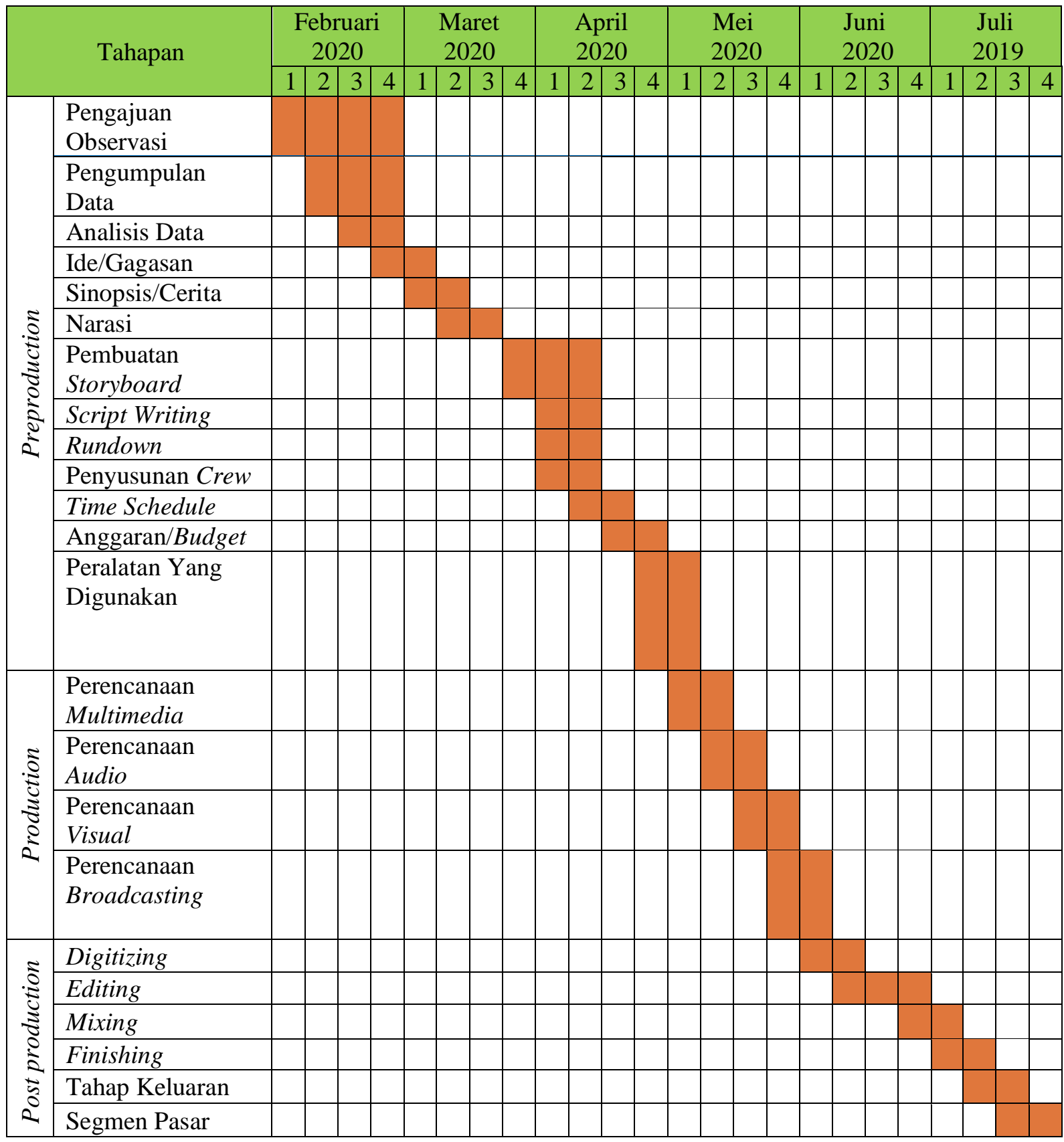


10. Peralatan yang digunakan

Peralatan yang digunakan dalam pembuatan video promosi ini menggunakan Laptop Acer Aspire 4.7, kamera Canon DSLR 1200D, Tripod, Memory Sandisk Ultra 32 GB, DVD RW dan Hardisk WD 1 TB.

\subsection{Production}

Production adalah tahap pengambilan gambar atau tahap implementasi dari hasil rancangan yang dilakukan di tahap pre production.

Pada tahap production untuk pembuatan suatu video promosi SMK Islam Terpadu Indra Bangsa Tangerang semua unsur teknis dan kreatif seperti naskah, talent, sinematografi dijalankan sesuai arahan sutradara juga didukung dengan pengambilan gambar video yang harus dibuat dengan baik.

\section{Program Visual}

Tampilan isi video promosi ini akan dirancang pada saat pembuatan sinopsis. Berikut ini adalah tampilan isi video promosi yang telah dibuat pada saat proses perancangan Konsep Produksi Media (KPM).

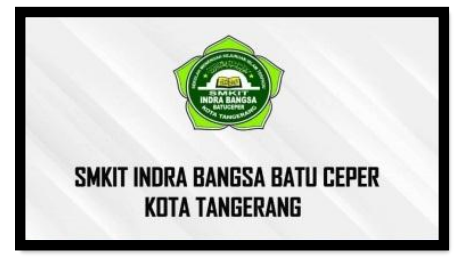

Gambar 12. Scene 1/ Menampilkan videobumper Opening Logo SMK Islam Terpadu Indra Bangsa Tangerang

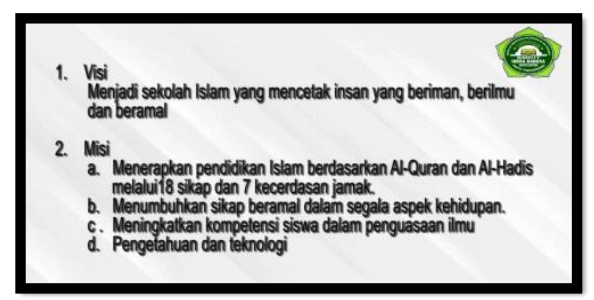

Gambar 14. Scene 3/ Menampilkan Visi \& Misi SMK Islam Terpadu Indra Bangsa

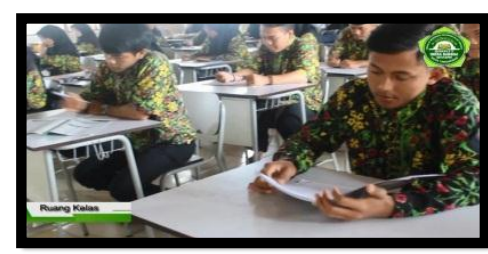

Gambar 16. INT/Scene 5/ Day/ Medium Shoot / Menampilkan Video Ruang Kelas SMK Islam Terpadu Indra Bangsa

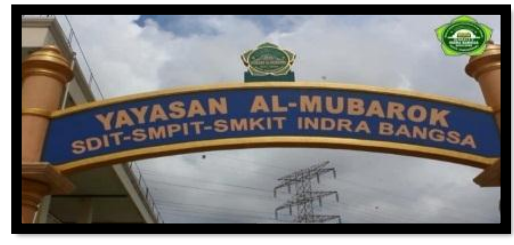

Gambar 13. EXT/Scene 2/ Day/Medium shot/ Menampilkan Tulisan Nama Sekolah

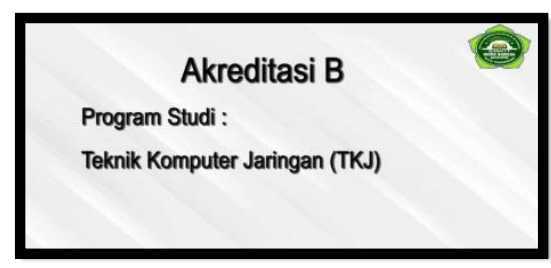

Gambar 15. Scene 4/ Scene 4 Menampilkan Akreditasi Sekolah SMK Islam Terpadu Indra Bangsa

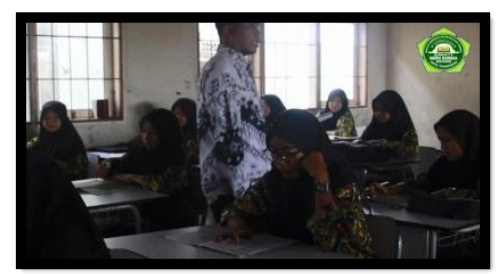

Gambar 17. INT/Scene 6/ Day/Medium Shot/ Menampilkan Video Kegiatan Belajar Mengajar Di Kelas 


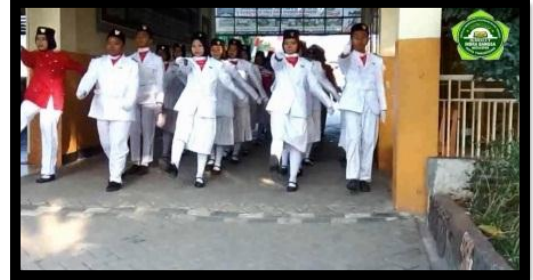

Gambar 18. EXT/Scene 7/Day/Long Shot/ Menampilkan Video Ekstrakurikuler Paskibra.

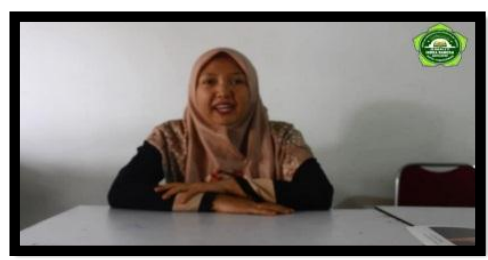

Gambar 20. INT/scene 9/day/Day/Close up/ Menampilkan Video Ajakan Bergabung di SMK Islam Terpadu Indra Bangsa

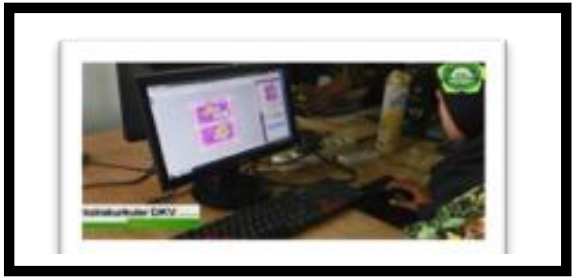

Gambar 19. INT/scene 8/Day/Over Shoulder shot/ Menampilkan Video Ekstrakurikuler DKV.

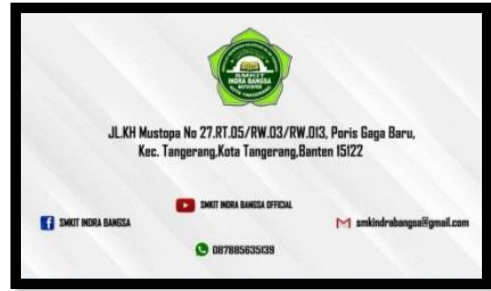

Gambar 21. Scene 10/ Day/ Menampilkan

Video Logo, Alamat, Nomor Telepon, Youtube, Facebook dan Email SMK Islam Terpadu Indra Bangsa

\subsection{Post Production}

Post production merupakan tahapan akhir dari Konsep Produksi Media, dimana pada proses ini merupakan keseluruhan hasil edit oleh editor sesuai dengan storyboard sehingga menjadi hasil finishing video. Dalam Tahap selanjutnya adalah Post Production, pada tahapan ini terdapat proses digitizing, editing, mixing, finishing, exporting dan segmen pasar.

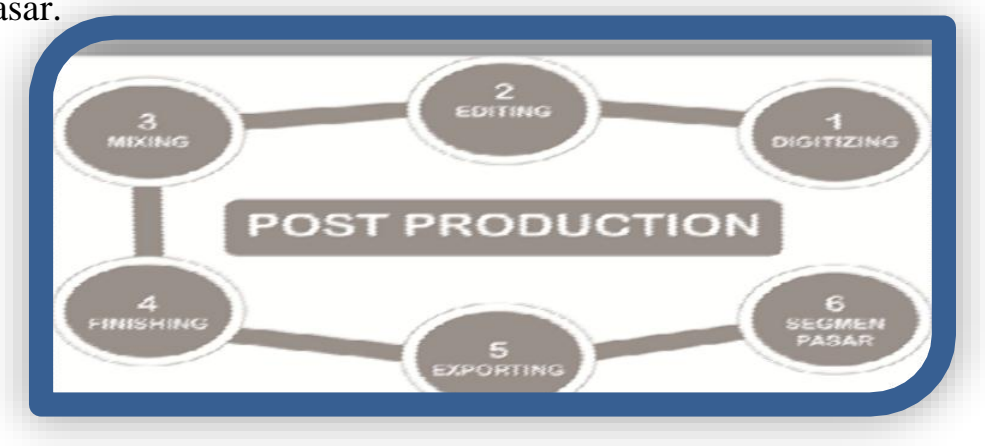

Gambar 22. Post Production

\section{Digitizing}

Proses digitizing merupakan tahap digitalisasi hasil dari pengambilan gambar yang masih analog kemudian diubah menjadi data digital dan disimpan agar bisa digunakan kembali saat diperlukan.

\section{Editing}

Proses editing ini merupakan tahapan yang memerlukan waktu cukup lama dan pemikiran yang matang karena pada tahap ini menggabungkan beberapa elemen penting dalam suatu pembuatan project seperti cut atau memotong video, menambahkan efek gerak, memilih dan 
menyusun hasil gambar shooting sesuai kebutuhan juga ide yang dimiliki sesuai naskah dan storyboard yang telah dibuat. Software yang digunakan untuk mengedit video promosi adalah Adobe Premiere Pro CS.

\section{Mixing}

Mixing merupakan sebuah penggabungan suara pada saat melakukan proses editing. Suara dalam proses mixing meliputi dubbing, music, dan effect suara. Ketiga unsur dalam proses tersebut haruslah disesuaikan dengan gambar shooting yang ditampilkan. Sesudah tahapan mixing ini boleh dikatakan bagian yang paling penting dalam post production ketika sudah selesai. Software yang digunakan untuk mengedit video promosi adalah Adobe Premiere Pro CS6.

\section{Finishing}

Pada tahap finishing ini merupakan tahap berikutnya dalam proses pengeditan video promosi namun juga harus melakukan pengecekan kembali apakah file tersebut bermasalah atau tidak (rusak atau hilang). Lalu melakukan pengecekan kembali pada bagian audio dan video yang harus sesuai dengan konsep yang dibuat. Pada tahap ini dilakukan proses export video dari Adobe Premiere Pro CS6 menjadi format video dengan ekstensi.mp4.

\section{Exporting}

Pada tahap ini setelah video promosi sudah melakukan proses digitizing, editing, mixing, dan finishing kemudian video promosi di export menggunakan software Adobe Premiere Pro CS6, dengan memilih format berkualitas full HD 1920x1080 dan frame rate 25 fps. Kemudian hasil render ini akan di upload ke dalam youtube "SMK Islam Terpadu Indra Bangsa Official" dan sosial media Facebook.

\section{Segmen Pasar}

Segmen pasar media video promosi ini untuk jangkauan luas yaitu : calon siswa/i, siswa/i transfer, relasi sekolah dan masyarakat umum. Dengan adanya video promosi ini diharapkan dapat menjangkau pangsa pasar khususnya di wilayah Kota Tangerang dan umumnya menjangkau ke seluruh Indonesia. Dengan adanya media video promosi ini dapat mencapai target pemasaran sekolah setiap tahunnya dan sekolah semakin dikenal masyarakat. Sebelumnya diketahui jumlah siswa/i yaitu 108 orang, setelah adanya video promosi ini, diharapkan SMK Islam Terpadu Indra Bangsa dapat meningkatkan jumlah calon siswa/i sebanyak 250 orang yang berminat untuk bergabung di sekolah tersebut, serta diharapkan lebih dikenal masyarakat.

\section{KESIMPULAN}

Berdasarkan dari hasil perancangan media video promosi, maka perancang menyimpulkan sebagai berikut: Tujuan dalam perancangan media video promosi yaitu menghasilkan konsep media video promosi yang kreatif dengan menampilkan audio, visual dan effect visual agar dapat menjadi daya tarik calon siswa dan siswi baru untuk bergabung di SMK Islam Terpadu Indra Bangsa. 


\section{SARAN}

Berdasarkan hasil penelitian yang sudah disimpulkan, terdapat beberapa saran yang diberikan, yaitu sebagai berikut: Disarankan kepada SMK Islam Terpadu Indra Bangsa agar setiap tahunnya dapat selalu memberikan pembaharuan informasi dengan update kepada masyarakat; Menggunakan video yang telah dibuat sebagai media promosi yang digunakan seterusnya serta terus diperbarui dengan memanfaatkan Youtube atau platfrom sosial media lain dan dapat menunjang informasi dan promosi untuk lebih menarik minat calon siswa/siswi baru dan masyarakat pada SMK Islam Terpadu Indra Bangsa.

\section{DAFTAR PUSTAKA}

[1] Widada,Sugeng. Adi Kusuma Wijaya Tama dan Nanda Lestari, 2020. Video Profile Sebagai Media Promosi Pada MTS Al-Husna YPIHN Curug Kabupaten Tangerang. Tangerang: Universitas Raharja.Journal CERITA. ISSN 2655-2574. Vol. 6, No. 1: 40.

[2] Syawal, Ardi. Manan Sailan, 2015. Peranan Panti Asuhan Dalam Pembentukan Moral Anak (Studi Pada Yayasan Panti Asuhan Bustanul Islamiyah, Kecamatan Panakkukang, Kota Makassar). Makassar: Universitas Negeri Makassar. Jurnal Tomalebbi. ISSN: 2355-6439. Vol. II, No. 3:34.

[3] Maulani, Giandari. Noviar Jalu Sasongko dan Ardi Mulyana, 2016. Pengembangan Media Promosi Pariwisata Kota Tangerang Dalam Bentuk Video Digital Pada Dinas Porparekraf.Tangerang : STMIK Raharja. Jurnal ICIT. ISSN : 2356 -5195. Vol.2, No.2.

[4] Sunarya, Lusyani. Nesya Elvina Ayudita dan Satria Agung Prabawa, 2018. Video Promosi Jurusan Sistem Informasi Berbasis Motion Graphic Pada STMIK Raharja Tangerang.Tangerang : Universitas Raharja. Journal SENSI. ISSN: 2461-1409. Vol. 4, No. 1

[5] Hardiansyah,Qodrat. Dinny Kurnia Hermawan dan Tajul Mutakin, 2018. Video Profile Sebagai Media Penunjang Informasi Dan Promosi Pada SMK Putra Tama Mandiri.Tangerang: Universitas Raharja. Jurnal ICIT. ISSN : 2356 -5195.Vol. 4 No.1.

[6] Permana,Agus Aan Jiwa. Ni Ketut Kertiasih dan I Putu Budhayasa, 2017. Video Profil Sebagai Sarana Promosi Efektif Dalam Menunjang Eksistensi Program Studi Manajemen Informatika.Bali: Universitas Pendidikan Ganesha. Jurnal Sains dan Teknologi. ISSN: 2303-3142. Vol.6 No.2.

[7] Wiratna, Haris. Rahmatsyam Lakoro, 2017. Perancangan Video Promosi Wisata Pantai Kabupaten Jember dengan Konsep Sinematik Infografis.Surabaya : Institut Teknologi Sepuluh Nopember. JURNAL SAINS DAN SENI ITS. ISSN: 2337 3520. Vol. 6, No. 2 